\title{
New Study: Spine Surgeons Take Care of Your Necks!
}

\section{Ken Hansraj*}

Orthopaedic Spine Surgeon, Nuvance Health, New York, USA

*Corresponding Author: Ken Hansraj, Orthopaedic Spine Surgeon, Nuvance Health, New York, USA.

Indian spine surgeons J Naresh-Babu, Viswanadha Arun-Kumar and DGS Ragu of the Mallika Spine Centre, Andhra Pradesh performed an observational study whose purpose was to analyze the surgeon's neck postures while performing lumbar spinal surgeries.

Lumbar spinal surgeries are on rising trend, and with increase in number of procedures, the average time spent by a spine surgeon performing surgical procedures is also increasing. The effect of operating posture on the surgeon's neck is unknown. From the studies conducted on usage of smartphones, abnormal neck postures, especially the forward head posture (FHP), were found to adversely affect the cervical spine of individuals.

Sixty video recordings (25 open transforaminal lumbar interbody fusions [TLIFs] and 35 lumbar decompression [LD] procedures - 15 with headlight and 20 with operating microscope) of surgeries performed by three spine surgeons of different heights were analyzed. Running videos of the surgeries were recorded concentrating on the surgeons with reflective markers taped to their surface landmarks corresponding to C7 spinous process, tragus of the ear, and outer canthus of the eye. Head flexion angle (HFA), neck flexion angle (NFA), and cervical angle (CA) were measured and analyzed.

During transforaminal lumbar interbody fusions, head flexion angle (HFA), neck flexion angle (NFA), were significantly higher during the phases of decompression and fusion $(\mathrm{P}<0.05)$. The average cervical angle of all surgeons was lower, thereby adversely affecting the cervical spine $\left(20.15^{\circ} \pm 5.05^{\circ}\right)$. During lumbar decompression [LD] procedures, cervical angle (CA) showed significant difference between usage of microscope and headlight $(\mathrm{P}<0.001)$.

Indian spine surgeons J Naresh-Babu, Viswanadha Arun-Kumar and DGS Ragu of the Mallika Spine Centre, Andhra Pradesh found that the surgeon's forward head posture (FHP) is frequently caused by a compromise between the need to perform surgery with hands, without elevating the arms, and simultaneous control of gaze at surgical field. The usage of microscope was found to reduce the stress on neck while performing surgery.

Dr. Ken Hansraj points out that with modern day operating room tables, that the patient can be rotated, cutting the need of the
Received: March 26, 2020

Published: April 07, 2020

(C) All rights are reserved by Ken Hansraj.

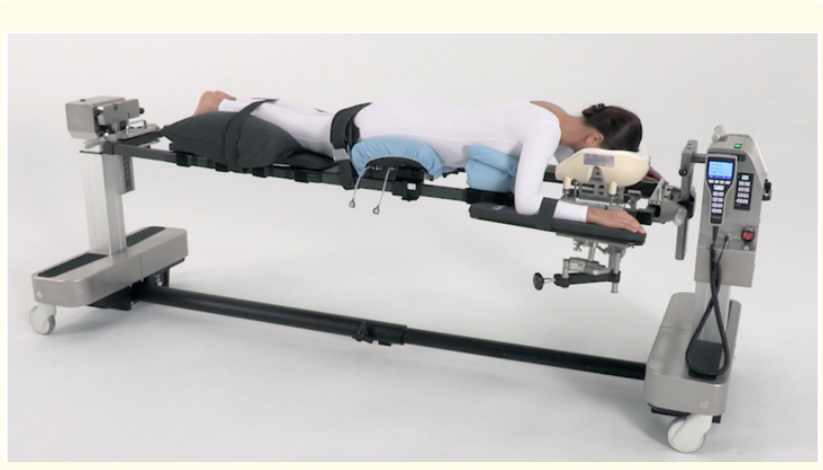

Figure 1: Courtesy of Mizuho OSI.

surgeon to look down and diminishing the tilt of the head flexion angle (HFA), neck flexion angle (NFA) and cervical angle (CA).

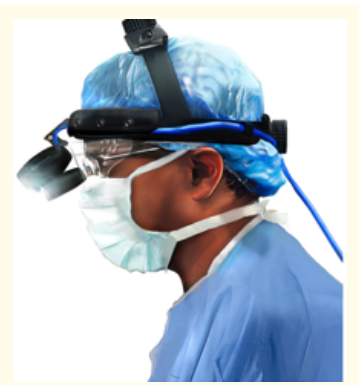

Figure 2

Furthermore, he notes that modern day surgical telescopes are built at a downwards angle further diminishing the spine surgeon's need to look down and hurt his or her neck.

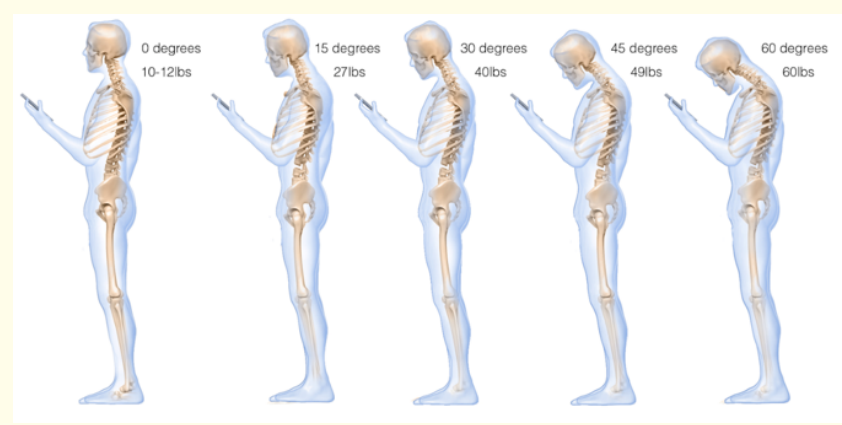

Figure 3

Good posture is essential

New York based internationally best-selling author and spinal surgeon Dr. Ken Hansraj expressed that people need to know that 
a mere 15 degrees tilt could double the forces on the neck in text neck.

Remember your mother saying, "Stop slouching"? You would think it goes without saying, but too many of us simply don't maintain good posture, which is critical for a healthy spine.

Good posture is defined as ears aligned with the shoulders and the "angel wings" or the shoulder blades, retracted. In proper alignment, spinal stress is diminished. It is the most efficient position to achieve the best posture possible.

Proper posture leads to a taller appearance, deeper breathing, improved well-being and increased energy with enhanced human performance. Many experts believe stooping and slouching could be associated with depression, weight gain, heartburn, migraines, anxiety and respiratory conditions.

\section{Assets from publication with us}

- Prompt Acknowledgement after receiving the article

- Thorough Double blinded peer review

- Rapid Publication

- Issue of Publication Certificate

- High visibility of your Published work

Website: https://www.actascientific.com/

Submit Article: https://www.actascientific.com/submission.php Email us: editor@actascientific.com

Contact us: +919182824667 